\title{
Identification of a novel human doublecortin-domain-containing gene (DCDC1) expressed mainly in testis
}

Received: 25 March 2003/ Accepted: 8 April 2003/Published online: 18 June 2003

(C) The Japan Society of Human Genetics and Springer-Verlag 2003

\begin{abstract}
Mutations in the X-linked gene doublecortex $(D C X)$ result in lissencephaly in males or subcortical laminar heterotopia (double cortex) in females. Recently, an evolutionarily conserved doublecortin (DC) domain important for microtubule binding and microtubule polymerization was defined according to detailed sequence analysis of DCX and DCX-like proteins. Subsequently we cloned a novel human cDNA that contained a DC domain during large-scale DNA sequencing of the human fetal brain cDNA library, and termed it doublecortin-domain-containing 1 (DCDC1). According to a search against the human genome database, $D C D C 1$ was mapped to $11 \mathrm{p} 13$. Expression analysis showed that $D C D C 1$ was mainly expressed in adult testis. Furthermore, the expression level of $D C D C 1$ in fetal brain was much higher than in adult brain.
\end{abstract}

Keywords DC domain - Double cortex - Microtubule · Testis $\cdot 11 \mathrm{p} 13$

Lissencephaly (LIS) is one of the most severe human cerebral cortical malformations (Dobyns and Truwit 1995), which is thought to result from a failure of neuronal migration. Besides the first lissencephaly-associated gene lissencephaly-1 (LIS1 or PAFA1B1) identified on chromosome $17 \mathrm{p} 13$, another gene named doublecortex (DCX, or XLIS) was found to be associated with classical type I lissencephaly in humans recently (Portes et al. 1998; Gleeson et al. 1998). Mutations in the $\mathrm{X}$-linked $D C X$ cause gross neocortical disorganization

L. Zeng and S. Gu contributed equally to this paper

L. Zeng $\cdot \mathrm{S} . \mathrm{Gu} \cdot \mathrm{Y} . \mathrm{Li} \cdot \mathrm{E} . \mathrm{Zhao} \cdot \mathrm{J} . \mathrm{Xu}$

$\mathrm{X}$. Ye $\cdot \mathrm{Q}$. Wu $\cdot$ L. Wang $\cdot$ Y. Xie $\cdot$ Y. Mao $(\bowtie)$

State Key Laboratory of Genetic Engineering,

Institute of Genetics, School of Life Sciences,

Fudan University, 200433 Shanghai, P.R. China

E-mail:ymmao@fudan.edu.cn

Tel.: + 86-21-65643573

Fax: + 86-21-65642502 (lissencephaly or "smooth brain") in hemizygous males, whereas heterozygous females show a mosaic phenotype with a normal cortex, as well as a second band of misplaced (heterotopic) neurons beneath the cortex ("double cortex syndrome"). It was found that DCX co-localized with the microtubules, bound microtubules directly, stabilized them and caused bundling (Horesh et al. 1999).

So far, the closest homologue of $D C X$ is a gene named doublecortin and CaM kinase-like 1 (DCAMKL1, also known as KIAA0369) (Omori et al. 1998). DCX and DCAMKL1 share homology throughout the entire DCX amino acid sequence, but DCAMKL1 is twice larger. The unique $\mathrm{C}$ terminus of DCAMKL1 contains a domain similar to $\mathrm{Ca}^{2+}$ /calmodulin-dependent (CAM) kinases. Both DCX and DCAMKL1 have microtubule binding and polymerization activities, and are coexpressed in migrating neurons in developing brain (Mizuguchi et al. 1999; Lin et al. 2000). These results suggested that DCX and DCAMKL1 might together form a signaling pathway that regulates microtubules in migrating neurons. Other $D C X$-like genes were also found to be associated with some important inherited diseases. For example, mutations in a retina-specific DCAMKL1-like gene named retinitis pigmentosa 1 $(R P l)$ cause autosomal dominant retinitis pigmentosa (Sullivan et al. 1999).

A novel cDNA clone was isolated from a large-scale DNA sequencing of the human fetal brain cDNA library, which was constructed by our laboratory (Xu et al. 2001). Its nucleotide sequence is available from GenBank under accession number AY247970 (Fig. 1a). This $1.7-\mathrm{kb}$ cDNA spans an open reading frame from nucleotide 203 to 1264 , encoding a putative 354-aminoacid protein with a predicted molecular mass of $39.8 \mathrm{kDa}$, and a predicted isoelectric point of 9.40. An in-frame stop codon was found at position 158-160. The presumed initiation codon has a Kozak consensus sequence. And a putative polyadenylation signal, AATAAA, was found near the $3^{\prime}$ end of the sequence. Thus, it was concluded that the coding sequence is complete. 
By using BlastP (NCBI web server, http://www.ncbi. nlm.nih.gov/BLAST), the deduced protein was shown to be homologous to some putative proteins (GenBank accession no. XP_158837, XP_242096, XP_158841, XP_034415, BAA96017, XP_289880, BAC26̄042, XP_283759, XP 230359, AAF08814, and AF194079) and DCX, with similarities from $46 \%$ to $81 \%$. Most of their homologous regions located between residues 170 and 246 in the deduced amino acid sequence of the cDNA we cloned. This region was later identified as a doublecortin domain (Bioinformatics Web server, http://www.isrec.isb-sib.ch/ software/PFSCAN_form.html) (Fig. 1b). Therefore, we termed this gene doublecortin domain containing 1 $(D C D C 1)$, in agreement with the HUGO Nomenclature Committee. The doublecortin (DC) domain is an evolutionarily conserved domain defined according to detailed sequence analysis of DCX and DCX-like proteins (Sapir et al. 2000). In the large majority of patients, missense mutations in DCX fall within the conserved regions, such as $\mathrm{Y} 125 \mathrm{H}, \mathrm{A} 71 \mathrm{~S}, \mathrm{R} 59 \mathrm{H} / \mathrm{L}, \mathrm{D} 62 \mathrm{~N}, \mathrm{G} 253 \mathrm{D}, \mathrm{R} 192 \mathrm{~W}$, and T203R. The domain commonly appears in the $\mathrm{N}$ terminus of proteins and consists of two tandemly repeated 80 -amino-acid regions. In vitro and in vivo experiments indicated that each repeat alone bound tubulin, while neither repeat was sufficient for co-assembly with microtubules. However, two tandem repeats were sufficient to mediate microtubule polymerization (Taylor et al. 2000). The DC domain of DCDC1 contains only one repeat. This means that DCDC1 might only have microtubule binding activity, but no ability to mediate microtubule polymerization. The absence of a signal peptide (PSORT II server, http://psort.nibb.ac.jp) and a transmembrane domain suggests that DCDC1 is a hydrophilic, intracellular protein. It might also have some other domains with unknown function.

By searching against the human EST database and the human genome database, we found the $D C D C 1$ gene to be represented by five ESTs and two genomic clones (accession nos. NT_030801.7, AL162614.25 and AL137804.7) from chromosome 11p13. Comparison of the cDNA sequence of $D C D C 1$ to the genomic sequence revealed that the $D C D C 1$ gene spanned about $107 \mathrm{~kb}$ of genomic DNA and consisted of nine exons. We could thus determine the complete exon-intron structure of the DCDCl gene (Table 1).

To investigate the expression pattern of $D C D C 1$ in different tissues, we used two human multiple tissue cDNA (MTC; Clontech, Palo Alto, Calif., USA) panels as PCR templates according to the manufacturer's protocol. The $D C D C 1$-specific primer pairs (DCDC1F: 5'-tgggtgatttctgcatttccaactaag-3'; DCDC1R: 5'-ata aacatcggcttcatggggtatatc- $\left.3^{\prime}\right)$ were designed to amplify a $0.7-\mathrm{kb}$ fragment. A G3PDH control primer pair included in the panels was used to verify the normalization of the MTC panels. A total of 36 cycles of amplification were performed using rTaq DNA polymerase (TaKaRa, Tokyo, Japan) in a total volume of $50 \mu \mathrm{l}$. All the reactions were paused after a total of 27 a

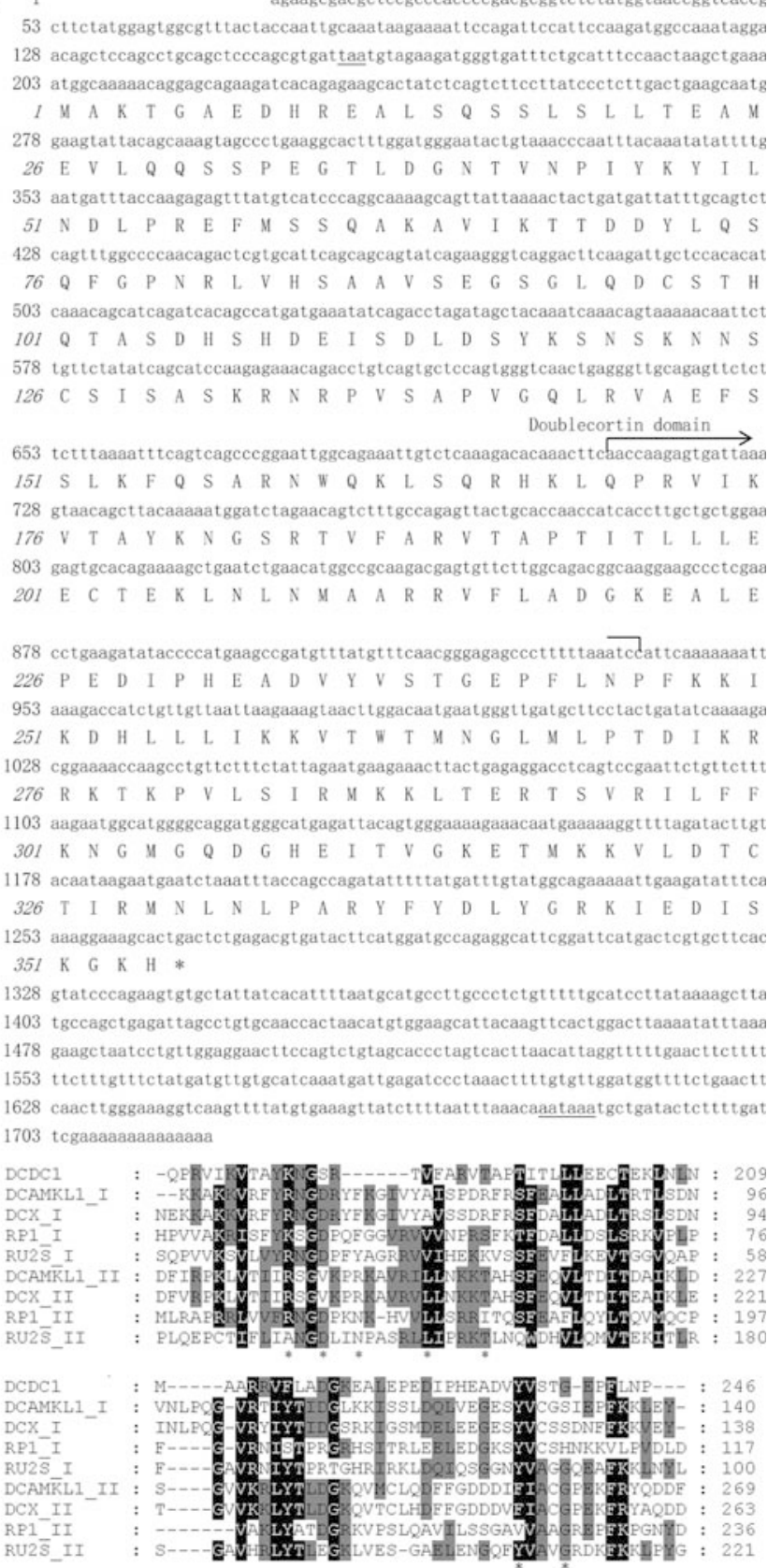

Fig. 1a, b The sequences and domain analysis of $D C D C 1$. a Sequence of the $D C D C l$ gene. The in-frame codons and polyadenylation signals are underlined. Amino acids are represented below the DNA sequences. The asterisk represents the stop codon. The arrow indicates the doublecortin (DC) domain. b Alignment of the DC domains in DCDC1 and other human DC-domain-containing proteins, including DCX (GenBank accession no. NP 000546; domain I: 48-138, domain II: 175-263), DCAMKL1 (accession no. NP_004725; domain I: 52-142, domain II: 181-269), RP1 (accession no. XP_129368; domain I: 30-117, domain II: 152-236), and RU2S (accession no. AAF23612; domain I: 12-100, domain II 134-221). Alignment was performed by Clustal W algorithms, and amino acids were shaded according to the degree of conservation using GeneDoc (http://www.cris.com/ Ketchup/genedoc.shtml): black (80-100\% similarity), and grey (60-80\% similarity). The positions of missence mutations in DCX that cause lissencephaly are shown by asterisks 
Table 1 Exon-intron boundary sequence of $D C D C 1$. Intron and exon nucleotide sequences are shown in lowercase and uppercase letters, respectively. Bold italic lettering indicates donor and acceptor splice sites. All sequences of the exon-intron junctions are consistent with the AG-GT rule

\begin{tabular}{|c|c|c|c|c|c|c|c|}
\hline \multicolumn{2}{|l|}{ Exon } & \multicolumn{2}{|l|}{ cDNA position } & \multirow[t]{2}{*}{ Splicing acceptor } & \multirow[t]{2}{*}{ Splicing donor } & \multicolumn{2}{|l|}{ Intron } \\
\hline Number & $\begin{array}{l}\text { Length } \\
\text { (bp) }\end{array}$ & Position at NT_030801.7 & $D C D C 1$ & & & Number & $\begin{array}{l}\text { Length } \\
\text { (bp) }\end{array}$ \\
\hline 1 & 78 & 10796482-10796405 & $1-78$ & & TTTACTACCAgtaagttcce & & \\
\hline 2 & 118 & $10762272-10762155$ & 79-196 & tattttccagATTGCAAATA & TCCAACTAAGgtacetggtt & 1 & 34,132 \\
\hline 3 & 170 & 10754994-10754825 & 197-366 & tcattttagCTGAAAATGG & ATTTACCAAGgtaagaacat & 2 & 7,160 \\
\hline 4 & 270 & $10734616-10734347$ & $367-636$ & tttcttccagAGAGTTTATG & GTCAACTGAGgtaatcaaag & 3 & 20,208 \\
\hline 5 & 157 & $10733096-10732940$ & $637-793$ & ttttcttcagGGTTGCAGAG & CATCACCTTGgtaactagtg & 4 & 1,250 \\
\hline 6 & 163 & $10732485-10732323$ & 794-956 & tttcttctagCTGCTGGAGG & AAAATTAAAGgtaaaaaga & 5 & 454 \\
\hline 7 & 206 & $10717560-10717355$ & $957-1162$ & tatcttctagACCATCTGTT & AATGAAAAAGgtaattttta & 6 & 14,762 \\
\hline 8 & 94 & $10692308-10692215$ & $1163-1256$ & tcctgcacagGTTTTAGATA & ATTTCAAAAGgtaagtggca & 7 & 25,046 \\
\hline 9 & 450 & 10689781-10689332 & $1257-1706$ & atcaaaacagGAAAGCACTG & & 8 & 2,433 \\
\hline
\end{tabular}

a

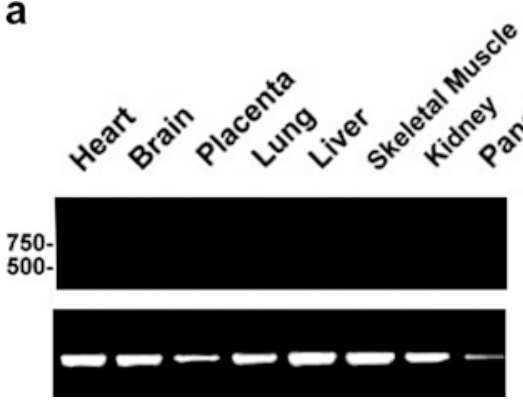

Fig. 2a, b Expression pattern of $D C D C 1$. a Reverse transcriptionPCR analysis of human adult tissues cDNA for $D C D C 1$ and $G 3 P D H$ (positive control). Results of 36 cycles (for $D C D C 1$ ) and 27 cycles (for $G 3 P D H$ ) of amplification are shown. b Reverse transcription-PCR analysis of human fetal brain and brain tissues cDNA for $D C D C 1$ and $G 3 P D H$ (positive control). Results of 38 cycles (for $D C D C 1$ ) and 27 cycles (for $G 3 P D H$ ) are shown

cycles, 30 cycles, 33 cycles and 36 cycles. Each time, 5- $\mu 1$ samples of each reaction mixture were removed to run on a gel, and the rest put back in the thermal cycler. The cycling conditions were as follows: $2 \mathrm{~min}$ at $94{ }^{\circ} \mathrm{C}$, followed by cycles of $30 \mathrm{~s}$ at $94{ }^{\circ} \mathrm{C}, 90 \mathrm{~s}$ at $68{ }^{\circ} \mathrm{C}$, with a 5 min $68{ }^{\circ} \mathrm{C}$ step to finish. When 27 cycles of amplification was performed, G3PDH (positive control) RT-PCR products were detected in all tissues tested. After 36 cycles the signal was detected in testis, lung, kidney and pancreas. However, the band in testis was much brighter than in either of the other tissues (Fig. 2a). Thus, we concluded that $D C D C 1$ was expressed mostly in testis.

We noticed that $D C D C 1$ cDNA could be isolated from fetal brain but could not be detected in adult brain tissue. We further used the cDNAs of these two tissues from MTC as PCR templates to compare the expression levels in fetal brain and adult brain. Both the primers and the cycling conditions were the same as above. After 38 cycles, it was found that the expression level of $D C D C 1$ in fetal brain was much higher than in adult brain (Fig. 2b). Further study should be made to corroborate DCDC1 as a microtubule-associated protein and to clarify the precise role of $D C D C 1$ gene in testis.
Acknowledgements This work was supported by the 863 project of P.R. China (grant no. 2001AA221181) and the National Science Foundation of China (30170345).

\section{References}

Dobyns WB, Truwit CL (1995) Lissencephaly and other malformations of cortical development. Neuropediatrics 23: $132-147$

Gleeson JG, Allen KM, Fox JW, Lamperti ED, Berkovic S, Scheffer I, Cooper EC, Dobyns WB, Minnerath SR, Ross ME, Walsh CA (1998) doublecortin, a brain-specific gene mutated in human X-linker lissencephaly and double cortex syndrome, encodes a putative signaling protein. Cell 92:63-72

Horesh D, Sapir T, Francis F, Wolf SG, Caspi M, Elbaum M, Chelly J, Reiner O (1999) Doublecortin, a stabilizer of microtubules. Hum Mol Genet 8:1599-1610

Lin PT, Gleeson JG, Corbo JC, Flanagan L, Walsh CA (2000) $D C A M K L 1$ encodes a protein kinase with homology to doublecortin that regulates microtubule polymerization. J Neurosci 20:9152-9161

Mizuguchi M, Qin J, Yamada M, Ikeda K, Takashima S (1999) High expression of doublecortin and KIAA0369 protein in fetal brain suggests their specific role in neuronal migration. Am $\mathbf{J}$ Pathol 155:1713-1721

Omori Y, Suzuki M, Ozaki K, Harada Y, Nakamura Y, Takahashi E, Fujiwara T (1998) Expression and chromosomal localization of KIAA0369, a putative kinase structurally related to Doublecortin. J Hum Genet 43:169-177

Portes V, Pinard JM, Billuart P, Vinet MC, Koulakoff A, Carrie A, Gelot A, Dupuis E, Motte J, Berwald-Netter Y, Catala M, Kahn A, Beldjord C, Chelly J (1998) A novel CNS gene required for neuronal migration and involved in $\mathrm{X}$-linked subcortical laminar heterotopia and lissencephaly syndrome. Cell 92:51-61 
Sapir T, Horesh D, Caspi M, Atlas R, Burgess HA, Wolf SG, Francis F, Chelly J, Elbaum M, Pietrokovski S, Reiner O (2000) Doublecortin mutations cluster in evolutionarily conserved functional domains. Hum Mol Genet 9:703-712

Sullivan LS, Heckenlively JR, Bowne SJ, Zuo J. Hide WA, Gal A, Denton M, Inglehearn CF, Blanton SH, Daiger SP (1999) Mutations in a novel retina-specific gene cause autosomal dominant retinitis pigmentosa. Nat Genet 22:255-259
Taylor KR, Holzer AK, Bazan JF, Walsh CA, Gleeson JG (2000) Patient mutations in doublecortin define a repeated tubulinbinding domain. J Biol Chem 275:34442-34450

Xu J, Zhou Z, Zeng L, Huang Y, Zhao W, Cheng C, Xu M, Xie Y, Mao Y (2001) Cloning, expression and characterization of a novel human REPS1 gene. Biochem Biophys Acta 1522:118121 